\title{
Dendrodendritic Synaptic Signals in Olfactory Bulb Granule Cells: Local Spine Boost and Global Low-Threshold Spike
}

\author{
Veronica Egger, Karel Svoboda, and Zachary F. Mainen \\ Cold Spring Harbor Laboratory, Cold Spring Harbor, New York 11724
}

In the mammalian olfactory bulb, axonless granule cells process synaptic input and output reciprocally within large spines. The nature of the calcium signals that underlie the presynaptic and postsynaptic function of these spines is mostly unknown. Using two-photon imaging in acute rat brain slices and glomerular stimulation of mitral/tufted cells, we observed two forms of action potential-independent synaptic $\mathrm{Ca}^{2+}$ signals in granule cell dendrites. Weak activation of mitral/tufted cells produced stochastic $\mathrm{Ca}^{2+}$ transients in individual granule cell spines. These transients were strictly localized to the spine head, indicating a local passive boosting or spine spike. $\mathrm{Ca}^{2+}$ sources for these local synaptic events included NMDA receptors, voltage-dependent calcium channels, and $\mathrm{Ca}^{2+}$-induced $\mathrm{Ca}^{2+}$ release $^{2}$ from internal stores. Stronger activation of mitral/tufted cells produced a low-threshold $\mathrm{Ca}^{2+}$ spike (LTS) throughout the granule cell apical dendrite. This global spike was mediated by T-type $\mathrm{Ca}^{2+}$ channels and represents a candidate mechanism for subthreshold lateral inhibition in the olfactory bulb. The coincidence of local input and LTS in the spine resulted in summation of local and global $\mathrm{Ca}^{2+}$ signals, a dendritic computation that could endow granule cells with subthreshold associative plasticity.

Key words: granule cell; olfactory; calcium; imaging; dendrite; dendritic spine; synaptic

\section{Introduction}

Granule cells (GCs) are small interneurons in the olfactory bulb that inhibit the bulbar principal neurons [mitral/tufted cells (M/ TCs)]. Synaptic processing by GCs is exotic from the perspective of conventional neurotransmission: lacking an axon, their large spines possess both presynaptic and postsynaptic machinery (Rall et al., 1966; Woolf et al., 1991a). The reciprocal M/TC-GC synapse involves a microcircuit contained within the spine (Shepherd and Greer, 1998): glutamate released from the M/TC triggers calcium influx into the spine, which leads to exocytosis of GABA back onto the same M/TC and thus M/TC "selfinhibition" (Jahr and Nicoll, 1980, 1982; Isaacson and Strowbridge, 1998). M/TCs also laterally inhibit one another through GCs, requiring transmitter release at sites distal to the activated synapses. Whereas in axon-bearing neurons this function is served by $\mathrm{Na}^{+}$-dependent action potentials (APs), selfinhibitory and lateral inhibitory M/TC interactions persist in vitro in the presence of TTX (Jahr and Nicoll, 1982; Isaacson and Strowbridge, 1998; Schoppa et al., 1998) or when somatic GC APs are prevented (Lagier et al., 2004). GCs appear to rarely spike in vivo (Wellis and Scott, 1990; Cang and Isaacson, 2003; Margrie and Schaefer, 2003). Thus, a substantial component of GC inhib-

Received Nov. 19, 2004; revised Jan. 29, 2005; accepted Feb. 23, 2005.

This work was supported by the Deutsche Forschungsgemeinschaft (V.E.), the Burroughs Wellcome Fund (Z.F.M.), the Searle Foundation (Z.F.M.), the National Institutes of Health (Z.F.M., K.S.), and the Howard Hughes Medical Institute (K.S.). We thank B. Burbach for technical help, Drs. N. Urban and T. Oertner for comments on the previous versions of this manuscript, P. Weber and Dr. E. Gutknecht (Hoffmann-La Roche, Basel, Switzerland) for the gift of mibefradil, and Dr. A. Konnerth for support.

Correspondence should be addressed to Veronica Egger at her present address: Institut für Physiologie der LudwigMaximilians-Universität, Pettenkoferstrasse 12, 80336 Munich, Germany. E-mail:veronica.egger@|rz.uni-muenchen.de. DOI:10.1523/JNEUROSCI.4746-04.2005

Copyright $\odot 2005$ Society for Neuroscience $\quad 0270-6474 / 05 / 253521-10 \$ 15.00 / 0$ itory output might occur in the subthreshold regimen (Rall et al., 1966).

There is little direct physiological data on GC synaptic signaling. Both NMDA receptor (NMDA-R) and voltage-dependent calcium channel (VDCC)-mediated $\mathrm{Ca}^{2+}$ entry have been implicated in self-inhibition based on recordings of M/TCs (Isaacson and Strowbridge, 1998; Schoppa et al., 1998; Chen et al., 2000; Halabisky et al., 2000; Isaacson, 2001). In our initial studies of GC calcium signaling, we observed spontaneous transients of unknown origin that were localized to spines (Egger et al., 2003). Although NMDA-R-mediated $\mathrm{Ca}^{2+}$ could account for local activation (Köster and Sakmann, 1998; Mainen et al., 1999a; Kovalchuk et al., 2000), it is controversial whether NMDA-Rmediated $\mathrm{Ca}^{2+}$ suffices to mediate self-inhibition (Schoppa et al., 1998; Chen et al., 2000; Isaacson, 2001). Conversely, opening of the VDCCs (present in both GC spines and dendrites) (Egger et al., 2003) would require electrical compartmentalization of synaptic voltage transients by spines (Rall and Rinzel, 1973; Brown et al., 1988). This interesting possibility would depend on more pronounced isolation than reported previously (Svoboda et al., 1996; Koch, 1999). Do spines remain isolated when activated by synaptic input from M/TCs? What sources of $\mathrm{Ca}^{2+}$ underlie dendrodendritically evoked spine transients?

Although it is known that lateral inhibition does not require TTX-sensitive $\mathrm{Na}^{+}$channels, the physiology of subthreshold signaling in GCs remains speculative. It has been hypothesized that this signal could be restricted to a local dendritic region (Woolf et al., 1991b; Woolf and Greer, 1994; Isaacson and Strowbridge, 1998). Such "dendritic subunits" have also been predicted based on compartmental models of other cell types (Koch et al., 1982; Shepherd and Brayton, 1987; Mel, 1993) and recently demonstrated in pyramidal cells (Polsky et al., 2004). Can dendroden- 
dritic M/TC inputs generate regional subthreshold activation patterns in granule cells? What cellular mechanisms underlie subthreshold lateral inhibition?

\section{Materials and Methods}

Preparation, solutions, and instrumentation. In all experiments, we prepared sagittal olfactory bulb brain slices (thickness, $350 \mu \mathrm{m}$ ) of juvenile Sprague Dawley rats (postnatal days 11-15). The preparation was performed in accordance with Cold Spring Harbor Laboratory guidelines for animal care. The intracellular solution contained the following (in mM): 130 K-methylsulfate, 10 HEPES, $4 \mathrm{MgCl}_{2}, 4 \mathrm{Na}_{2} \mathrm{ATP}, 0.4 \mathrm{NaGTP}$, $10 \mathrm{Na}$-phosphocreatine, and 2 ascorbate, $\mathrm{pH} 7.2$. For imaging, $100 \mu \mathrm{M}$ of the calcium-sensitive dye OGB-1 (Oregon Green 488 BAPTA-1) (Molecular Probes, Eugene, OR) was added. The extracellular artificial CSF (ACSF) was bubbled with carbogen and contained the following (in mM): $127 \mathrm{NaCl}, 25 \mathrm{NaHCO}_{3}, 1.25 \mathrm{NaH}_{2} \mathrm{PO}_{4}, 25$ glucose, $2.5 \mathrm{KCl}, 1 \mathrm{MgCl}_{2}$, and $2 \mathrm{CaCl}_{2}$. The junction potential was $-5 \mathrm{mV}$. Pharmacological agents used in some experiments were APV, thapsigargin (both from Tocris Cookson, Bristol, UK), and mibefradil (gift from Hoffman-La Roche, Basel, Switzerland). All experiments were performed at room temperature $\left(21^{\circ} \mathrm{C}\right)$.

Neurons were visualized with infrared-differential interference contrast (DIC) optics. Two-photon excitation at $810 \mathrm{~nm}$ was provided by a Ti:sapphire solid-state laser system (Mira and Verdi; Coherent-AMT, Kitchener, Ontario, Canada). For a more detailed description of the custom-built two-photon microscope, see Mainen et al. (1999b). Somatic whole-cell patch-clamp recordings were performed with an Axopatch 200B (Axon Instruments, Union City, CA). Pipette resistances were 4-7 M $\Omega$, and series resistances 10-35 $\mathrm{M} \Omega$.

To generate M/T cell synaptic input onto GCs, a glass electrode filled with $\operatorname{ACSF}\left(R_{\mathrm{P}}\right.$ of $\left.\approx 1 \mathrm{M} \Omega\right)$ and connected to an Isoflex stimulator (A.M.P.I., Jerusalem, Israel) was placed into a glomerulus within the slice before patching. Next, the direction of M/TC apical dendrites was followed downward from the glomerulus into the slice, and a GC vertically below these M/TCs was patched and held in current-clamp mode (Fig. 1). GCs that required $>20 \mathrm{pA}$ of holding current were rejected. In most of these GCs, a single pulse of stimulation resulted in a measurable EPSP or even an AP at higher stimulation intensity. Only GCs with considerable responses (EPSP amplitude $>5 \mathrm{mV}$ ) were used for additional experiments. After a filling time of $\sim 10 \mathrm{~min}$, calcium transients were imaged in line-scan mode (temporal resolution, $2 \mathrm{~ms}$ ) at different locations along the apical dendrite of GCs and within its spines (Figs. 2, 3). Each spine was tested with $\geq 10$ stimuli at a frequency of $0.1 \mathrm{~Hz}$ for synaptic calcium responses. Often, paired stimuli ( $20 \mathrm{~ms}$ interval) were used to enhance the success rate during searching. In responsive spines, line scans were performed across spine and adjacent dendrite, again at $0.1 \mathrm{~Hz}$. For comparison, responses to APs evoked by somatic current injection (sAP) were also measured. In most cases, no more spines were screened once a responsive spine was found, unless its responses were too rare or too small. There was no noticeable rundown of local synaptic calcium responses with time (average of $91 \pm 11 \%$ of baseline after $15 \min ; n=4$ spines).

To test the mitral cell firing patterns evoked by our stimulus protocol, we patched and recorded from mitral cells after recording from a responsive GC nearby $(<50 \mu \mathrm{m})$, with unaltered placement of the stimulation electrode. At the stimulus intensities used to evoke GC signals in the imaging experiments $(0.01-10 \mathrm{~mA})$, mitral cell responses were similar to data reported by others. The average resting potential was $-60 \mathrm{mV}(n=$ 8 mitral cells). At the maximal stimulation intensity $(10 \mathrm{~mA})$, we could elicit $\mathrm{Na}^{+}$spikes in seven of eight mitral cells. From threshold up to the maximal stimulation intensity of $10 \mathrm{~mA}$, mitral cells would respond with a single spike (Shepherd, 1963; Hamilton and Kauer, 1988). Below threshold, mitral cells displayed lasting depolarizations, fairly independent of stimulus intensity (Chen and Shepherd, 1997; Schoppa and Westbrook, 1999). The transition between subthreshold response and spike was usually more abrupt than for GCs, which is attributable to the more depolarized resting potential and possibly also to all-or-noneactivation of glomeruli (Schoppa and Westbrook, 1999; Wachowiak et al., 2004).
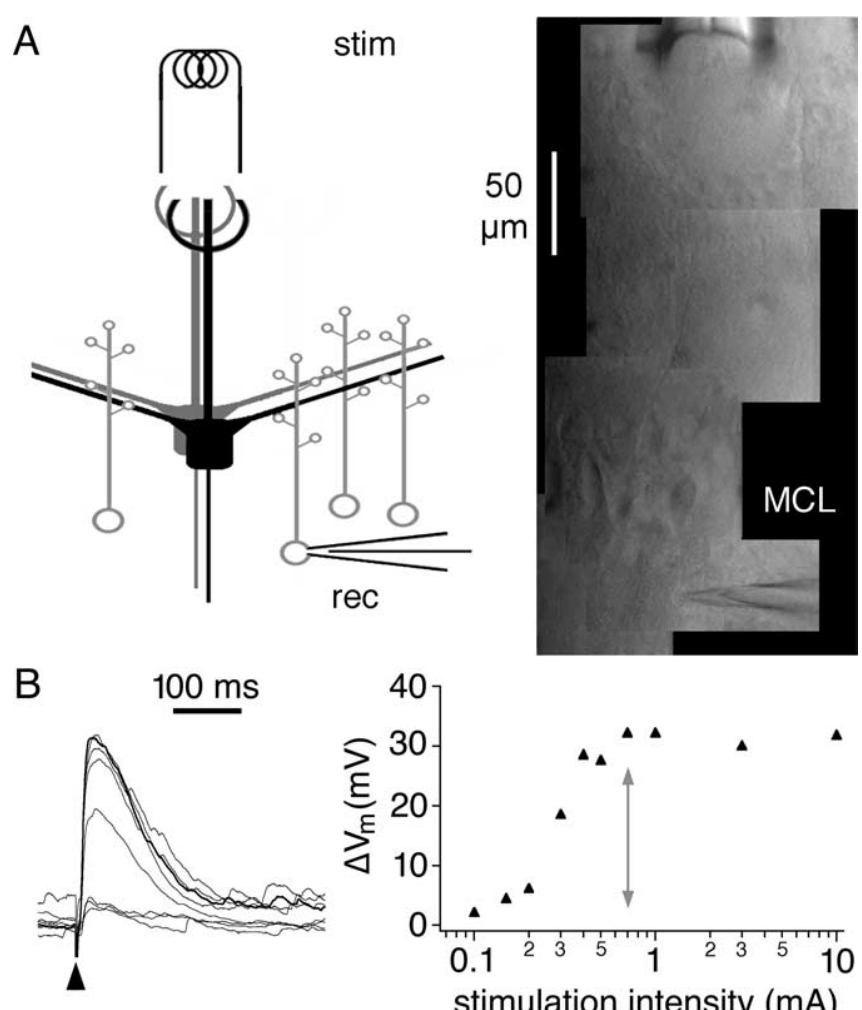

C
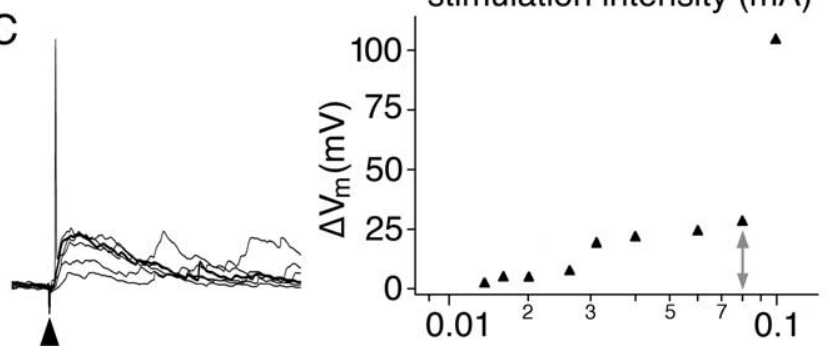

Figure 1. Glomerular stimulation allows for specific activation of M/TC inputs to GCs. A, Schematic and DIC video image of stimulation paradigm. To achieve stimulation of M/TC inputs, a stimulation electrode (stim) was placed into a glomerulus (note the faint ring of periglomerular cells in the video image). The direction of MC apical dendrites within the slice was then used to find the region in the $\mathrm{MCL}$ that would likely project to the glomerulus. A GC below this region was then patched (rec) and filled with calcium dye. B, Left, EPSPs in a GC recorded at the soma in response to increasing stimulation strength. Same voltage scale as on $y$-axis of the right panel. Black arrow, Stimulation artifact, clipped. Right, Input- output relationship for this GC. The gray arrow marks the stimulation strength that just saturates the response. This stimulation

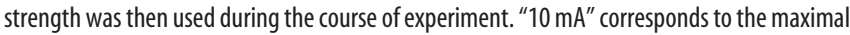
stimulation strength. $\boldsymbol{C}$, Same as in $\boldsymbol{B}$ but for a GC that responded with action potentials at stronger synaptic stimulation. Same time scale as in $\boldsymbol{B}$. The gray arrow marks the stimulation strength that was then used during the course of the experiment.

The small size of granule cells promoted fast filling, but, perhaps also because of their size, cells usually deteriorated abruptly $\sim 25-45 \mathrm{~min}$ after patching, precluding longer recording protocols such as drug washout. All investigated GCs were mature, i.e., bearing spines and capable of spiking (Petreanu and Alvarez-Buylla, 2002; Carleton et al., 2003).

Data analysis. Imaging and electrophysiological data were recorded and analyzed with custom software based on Matlab (MathWorks, Natick, MA) (Scanimage) (Pologruto et al., 2003) and Igor (WaveMetrics, Lake Oswego, OR). To measure changes in calcium, fluorescence was collected while scanning in a line that intersected the region(s) of interest. Fluorescence $F(t)$ was then averaged over the region(s) of interest. Baseline fluorescence $F_{0}$ was measured for $50 \mathrm{~ms}$ before the stimulus, and $\Delta F / F$ was calculated as $(\Delta F / F)(t)=\left(F(t)-F_{0}\right) / F_{0} .(\Delta F / F)_{\text {sAP }}$ corresponds to the fluorescence transient evoked by stimulation with a single AP evoked by somatic current injection, whereas $(\Delta F / F)_{\text {syn }}$ reflects a 

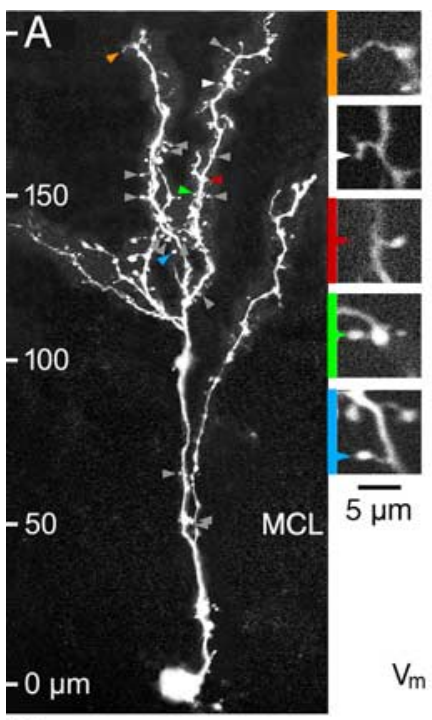

Mhn
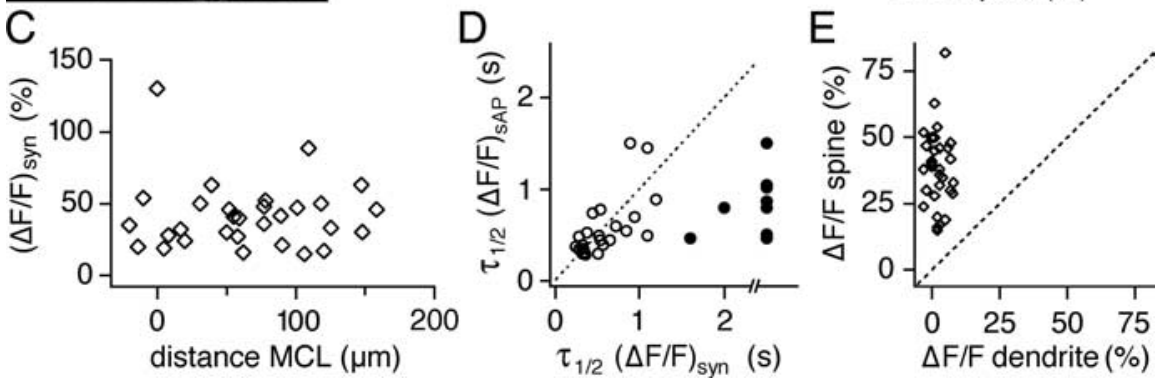

Figure 2. Single M/TC inputs activated by glomerular stimulation result in local $\mathrm{Ca}^{2+}$ influx into $\mathrm{GC}$ spines. $\boldsymbol{A}$, Left, Scan of an individual granule cell with locations of spines tested for synaptic responses. MCL marks the position of the mitral cell layer. Gray arrowheads mark unresponsive spines, and colored arrowheads mark responsive spines. Nineteen spines were tested. Right, Snapshots of the responsive spines and one unresponsive spine shown at the magnification used for line scans (calibration below) and, to the right, averaged $(\Delta F / F)_{\text {syn }}$ recorded from these spines. For every spine, averaged successes and failures are shown. Because the "white spine" represents an unresponsive spine, all respective recordings were averaged. The black trace at the bottom shows the averaged EPSP recorded at the GC soma. $\boldsymbol{B}$, Individual line scans recorded in the "red spine." Calibration as in $\boldsymbol{A}$. Both successes and failures are shown. Gray traces are recorded in the adjacent dendrite, illustrating the localization of synaptic responses to the spine head. The bottom plot summarizes the amplitudes of all recorded traces in the red spine versus the amplitudes of the same events in the adjacent dendrite. $C$, Mean response amplitude $(\Delta F / F)_{\text {syn }}$ of all active spines in this study versus their distance from the MCL. $D$, Scatter plot of decay time constants of AP-evoked signals $(\Delta F / F)_{\text {sAP }}$ versus half-duration of synaptic signal $(\Delta F / F)_{\text {syn }}$ in the same spines. Filled data points, Half-duration of synaptic signal at least twofold longer than the decay time constant of AP-mediated transient. Data points left of $2.5 \mathrm{~s}$ on the $y$-axis, Synaptic spine signal $(\Delta F / F)_{\text {syn }}$ too slow for measurement of half-duration (within a time window of $1 \mathrm{~s}$ per line scan). $\boldsymbol{E}$, Scatter plot of all mean response amplitudes $(\Delta F / F)_{\text {syn }}$ in active spines versus in their respective adjacent dendrites.

transient evoked by synaptic inputs to a spine and $(\Delta F / F)_{\text {LTS }}$ reflects a low-threshold spike (LTS) signal evoked by sufficiently large synaptic inputs.

Additional data analysis, such as amplitude and failure analysis, was performed only for spines responding with a signal-to-noise ratio $>2$ (evaluated within windows of 10 points in individual traces), which held for the majority of spines. Because test stimuli were limited to 10 and putative responses with a low signal-to-noise ratio were excluded, the resulting failure rates represent a lower estimate.

Only averaged synaptic transients with small noise levels after slight smoothing (window of five points) were used for kinetic analysis. The decay of synaptic signals was determined in terms of their half-duration $\left(\tau_{1 / 2}\right)$ rather than fitted with a single exponential $(\tau)$, because they often displayed an initial plateau phase.

For the evaluation of the voltage dependence of synaptic inputs, data [EPSP and $(\Delta F / F)_{\text {syn }}$ amplitudes and baseline fluorescences $F_{0}$ ] were normalized to their value at resting potential $(-70 \mathrm{mV})$ before averaging across spines.

In all the spines that were used for the analysis of summation of global and local $\mathrm{Ca}^{2+}$ signals, $\Delta F / F$ amplitudes of the individual components and the summated signals were well below saturation levels.
To assess statistical significance levels, the nonparametric Wilcoxon's matched-pairs signed-ranks test was applied for comparing paired data sets, and averages \pm SD are given, unless stated otherwise.

\section{Results \\ Using glomerular stimulation for synaptic activation}

We studied synaptically evoked calcium signals at the level of individual spines using two-photon imaging in acute rat brain slices. To activate exclusively M/TC inputs, we stimulated M/TC dendritic tufts within a glomerulus. Stimulation of the glomerular layer has been used previously in olfactory bulb preparations to mimic sensory input and study M/TC input to GCs (Schoppa et al., 1998; Schoppa and Westbrook, 1999). The stimulation of individual glomeruli allowed us to image M/TC-GC dendrodendritic synaptic input at the level of individual GC spines. Figure 1 shows the placement of stimulation electrode and recording pipette and characteristic EPSPs in a GC in response to increasing stimulation strength. The resting potential of GCs was approximately -70 $\mathrm{mV}$ (Egger et al., 2003). To maximize the chance of finding an activated spine, stimulation intensity was adjusted to the level at which saturation of the EPSP began (Fig. $1 B$ ). Saturation was determined by the size of input that could be recruited given the placement of the stimulation electrode in a given experiment and therefore does not represent an intrinsic parameter of the GC (see Materials and Methods). Under this condition, the average EPSP amplitude was $23 \pm 10 \mathrm{mV}$ (Fig. $3 E$ ), and 60 of 599 tested spines (found in 42 of 90 cells) were responsive to at least 1 of $\sim 10$ test stimuli. Most spines were located on GC apical dendrites in or above the mitral cell layer (MCL), in which reciprocal synapses are formed. The remainder $(n=5)$ were located on the proximal apical dendrites below the MCL. Sodium APs could be elicited synaptically in 55\% of GCs (Fig. 1C); in those cases, we used subthreshold stimulus amplitudes. All cells in the study responded with APs to short depolarizations at the soma (sAPs).

\section{Local synaptic activation}

Successful synaptic activation of a spine produced robust $\mathrm{Ca}^{2+}$ transients (Fig. 2) that occurred stochastically with an average failure rate of $47 \pm 28 \%$ (range, 5-90\%; see Materials and Methods). Anatomical data imply a very low number of reciprocal synaptic contacts per connected M/TC-GC pair (one or two) (Woolf et al., 1991a), and thus synaptic transmission between $\mathrm{M} / \mathrm{TC}$ and GCs is quite reliable on average. The actual reliability could be even higher because of failures of AP propagation in $\mathrm{M} / \mathrm{TC}$ lateral dendrites in our experiment (Margrie et al., 2001; Xiong and Chen, 2002).

$\mathrm{Ca}^{2+}$ transients had a mean $(\Delta F / F)_{\text {syn }}$ amplitude in the spine of $40 \pm 21 \%$ (range, $15-130 \%$; median, $55 \% ; n=34$ spines). 

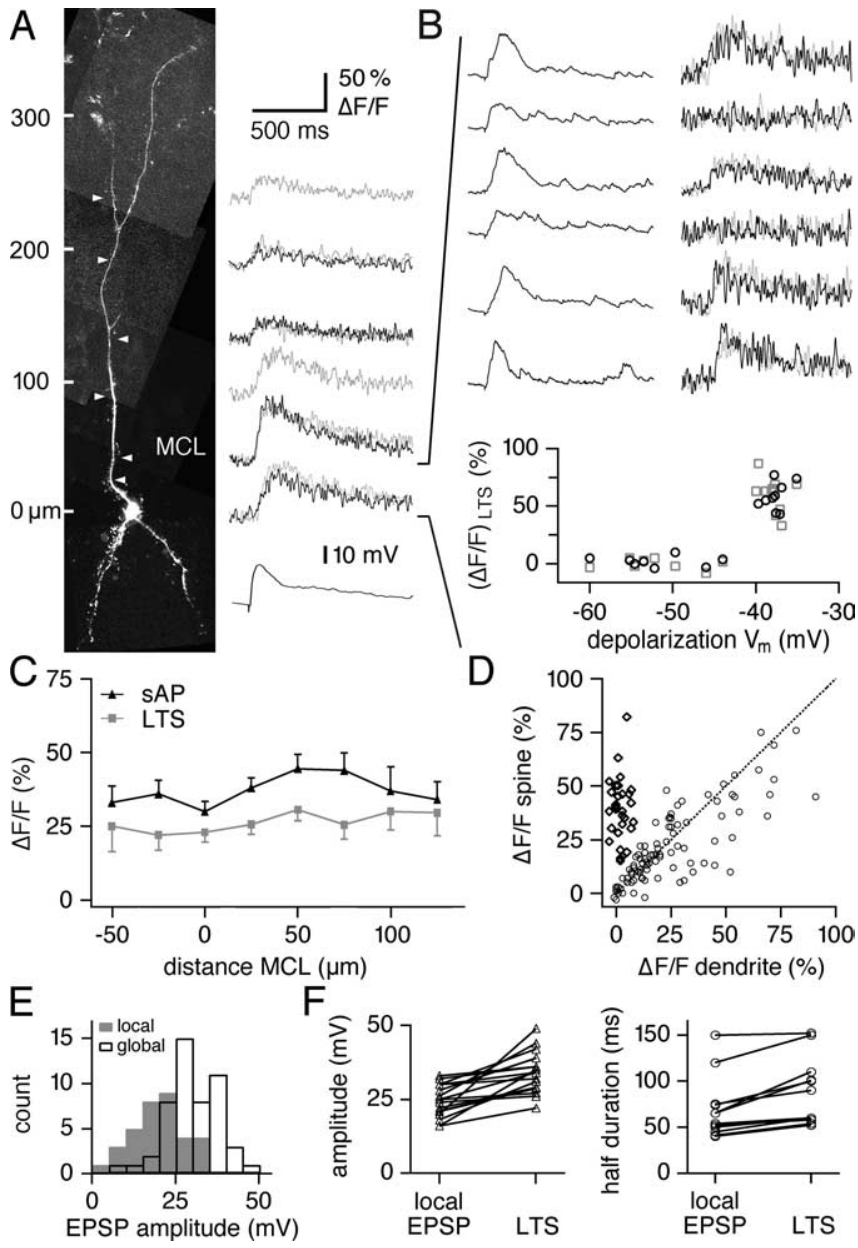

Figure 3. Large EPSPs evoked by glomerular stimulation cause global $\mathrm{Ca}^{2+}$ influx. A, Left, Scan of an individual granule cell with locations of line scans (white arrowheads). MCL marks the position of the mitral cell layer. Right, Averaged line scans of $\Delta F / F$ transients in spines (black) and dendrites (gray) recorded at the locations marked to their left. The black trace at the bottom shows the averaged EPSP recorded at the soma. $\boldsymbol{B}$, Consecutive individual EPSPs and corresponding line scans recorded at the most proximal location. Calibration as in $\boldsymbol{A}$. Note the correlated fluctuations in EPSP amplitude and $\Delta F / F$ transient amplitudes. The bottom plot summarizes the amplitudes of all $\Delta F / F$ transients at this location versus the maximal depolarization obtained by the concomitant EPSPS. C, Averaged $\Delta F / F$ transients caused by LTSs (gray markers) and sAPs (black markers), binned according to the distance of the recording site to the mitral cell layer. Data are from 48 cells and 137 dendritic locations. The analogous profiles for spines do not differ significantly. $D$, Scatter plot of all mean response amplitudes $(\Delta F / F)_{\text {LTS }}$ (open circles) and $(\Delta F / F)_{\text {syn }}$ (diamonds) in spines versus the respective adjacent dendrites. $\boldsymbol{E}_{\text {, }}$ Distribution of all mean EPSP amplitudes used in the experiments. The gray bars represent cells in which only local responses were found, and the white bars represent cells in which a global LTS signal was observed. $\boldsymbol{F}$, Changes in mean EPSP amplitude and half-duration that accompanied stochastic fluctuations between EPSPs that were linked to global LTS calcium signals and those that were not, at constant stimulation strength (as in $\boldsymbol{B}$ ). $n=12$ cells, several EPSPs averaged for each condition.

These amplitude values were well below the $\Delta F / F$ amplitudes achieved by trains of APs in GCs under similar conditions (Egger et al., 2003) and are therefore far from dye saturation for most spines. Synapses were found all over the GC dendrites (Fig. 2C). The location of a spine and its $(\Delta F / F)_{\text {syn }}$ amplitude were uncorrelated $(r=0.01)$. Synaptic calcium transients were strictly localized to the spine head, with little signal in the adjacent dendrite $(3 \pm 4 \%)$ (Fig. $2 B, E)$. This localization of $(\Delta F / F)_{\text {syn }}$ to the spine appears stronger than in other excitatory neurons (see Discussion).

Whereas transients attributable to APs evoked by somatic cur- rent injections typically rose in $<20 \mathrm{~ms}(15 \pm 7 \mathrm{~ms}$ in 87 dendritic locations; spines not significantly different), most synaptic transients in active spines rose slowly [mean rise time $(\Delta F / F)_{\text {syn }}, 84 \pm$ $28 \mathrm{~ms}$; range, $40-138 \mathrm{~ms} ; n=22$ ]. The half-duration $\tau_{1 / 2}$ of $(\Delta F / F)_{\text {syn }}$ across spines was considerably more variable than the decay time constant $\tau$ of $(\Delta F / F)_{\mathrm{sAP}}$ at the same sites and distributed in a bimodal manner, comprising a subset of very slow synaptic transients (Fig. $2 D$ ) (see also Fig. $5 B$ ). In most cases, $\tau_{1 / 2}$ for synaptic and $\tau$ for sAP-evoked $\Delta F / F$ transients were quite similar. Using an arbitrary cutoff (half-durations no more different than twofold), we divided the transients into two groups. For the 28 of 39 "normal" cases, half-durations were similar for synaptic and AP stimuli and highly correlated $\left(\tau_{1 / 2 \_ \text {syn }}\right.$ of $600 \pm 300 \mathrm{~ms} ; \tau_{\mathrm{sAP}}$ of $610 \pm 360 \mathrm{~ms} ; r=0.65, p<0.005)$. In the remaining 11 cases, the synaptic $\tau_{1 / 2}$ was $>1500 \mathrm{~ms}$ and often too slow to be determined. Although the underlying mechanism remains to be elucidated, a subpopulation of these "slow spines" displayed a high degree of spontaneous activity (Egger et al. 2003), which appeared to be enhanced after synaptic stimulation and which contributed to the slow kinetics of averaged $\mathrm{Ca}^{2+}$ signals.

\section{Low-threshold calcium spike}

In addition to individual spine responses, larger glomerular EPSPs were often accompanied by widespread $\mathrm{Ca}^{2+}$ influx in both dendrites and spines ( $n=48$ cells) (Fig. $3 A, C)$. Several observations suggested that an active event caused this signal, presumably an LTS (Huguenard, 1996), the signature of which has been observed previously at the GC soma (Egger et al., 2003; Pinato and Midtgaard, 2003).

(1) The $\mathrm{Ca}^{2+}$ influx was all-or-none in nature. We frequently observed near-threshold EPSPs in which trial-by-trial variations resulted in stochastic generation of calcium influx ( $n=17$ cells) (Fig. 3B). Moreover, $(\Delta F / F)_{\text {LTS }}$ signals did not increase gradually with the EPSP amplitude but with a discontinuous step (Fig. 3B, bottom).

(2) Compared with EPSPs subthreshold for the LTS signal, suprathreshold EPSPs in the same cell and at the same stimulation intensity were significantly broader (half-duration of $84 \pm$ 37 vs $66 \pm 32 \mathrm{~ms} ; n=13$ cells; $p<0.001)$ and larger ( $34 \pm 8$ vs $23 \pm 5 \mathrm{mV} ; n=13 ; p<0.001)$, indicating the activation of voltage-dependent channels (Fig. $3 F$ ). However, such a differentiation was less obvious across cells because the distributions for sub- and supra-LTS-threshold EPSP amplitudes and halfdurations overlapped considerably (Fig. 3E).

(3) Similar to sAP-evoked calcium transients (Egger et al., 2003), $(\Delta F / F)_{\text {LTS }}$ signals were of equal amplitude in dendrites and spines when spines were not also directly synaptically activated (mean amplitude of spines, $23 \pm 16 \%$; average ratio of spine/dendrite, $1.05 \pm 0.49 ; n=80$ ). This observation also provided an additional criterion to differentiate between global and local signals, as illustrated in Figure $3 D$, because local synaptic signals were localized to spines.

The properties of low-threshold $\mathrm{Ca}^{2+}$ spikes (Miyakawa et al., 1992; Markram and Sakmann, 1994; Wei et al., 2001) make the $(\Delta F / F)_{\text {LTS }}$ a likely candidate for AP-independent lateral inhibition (Isaacson and Strowbridge, 1998) (see Discussion). However, although regional subthreshold signaling has been long suggested in GCs as a substrate for local lateral inhibition (Woolf et al., 1991b; Woolf and Greer, 1994; Isaacson and Strowbridge, $1998)$, we never observed the calcium spike signal $(\Delta F / F)_{\text {LTS }}$ to be restricted to a small dendritic region or dendritic branch only, in contrast to other low-threshold $\mathrm{Ca}^{2+}$ spikes (Eilers et al., 1995; Wei et al., 2001). Instead, like the sAP-evoked calcium transients 
(Egger et al., 2003), $(\Delta F / F)_{\text {LTS }}$ appeared throughout all areas of the dendritic tree of examined GCs, indicating that it was global in nature (Fig. $3 A, C$ ).

The amplitudes of $(\Delta F / F)_{\text {LTS }}$ were robust but, on average, smaller than sAP-evoked responses $(\Delta F / F)_{\text {sAP }}$ in the same dendritic location $(22 \pm 17$ vs $42 \pm 25 \%$; $n=137 ; p<0.001)$ (Fig. $3 C)$. The time course of $(\Delta F / F)_{\text {LTS }}$ was comparable with that of local synaptic transients in active spines [rise time $(\Delta F / F)_{\text {LTS }}$, $88 \pm 54 \mathrm{~ms}$ in dendrites, $n=53 ; 85 \pm 53 \mathrm{~ms}$ in spines, $n=36]$. The half-duration of global calcium spike signals was significantly longer than the decay time constant of action potentialevoked transients $\left[(\Delta F / F)_{\text {LTS }}: \tau_{1 / 2}\right.$ of $900 \pm 520 \mathrm{~ms}$ in dendrites, $n=38 ; \tau_{1 / 2}$ of $820 \pm 410 \mathrm{~ms}$ in spines, $n=22$; vs $(\Delta F / F)_{\mathrm{sAP}}: \tau$ of $710 \pm 350$ and $690 \pm 380 \mathrm{~ms}$ in same locations; $p<0.01$ and $p<$ $0.02]$.

\section{Mechanism of low-threshold calcium spike}

Low-threshold calcium spikes are mediated by T-type calcium channels (T-channels) (Huguenard, 1996). Previous experiments have shown that T-channels are present in both GC dendrites and spines, as reflected in a considerable voltage dependence of sAP-evoked $\mathrm{Ca}^{2+}$ transients and strong $\mathrm{Ca}^{2+}$ entry in response to subthreshold depolarizations above $-40 \mathrm{mV}$ (Egger et al., 2003). Moreover, the T-channel antagonist mibefradil blocks low-voltage-activated (LVA) signals in GCs (Egger et al., 2003; Pinato and Midtgaard, 2003). Indeed, in our present study, mibefradil $(10 \mu \mathrm{M})$ blocked $(\Delta F / F)_{\text {LTS }}$ similarly in dendrites and spines $(16 \pm 11$ and $9 \pm 8 \%$ of control; $n=8$ and $n=6 ; p<0.01$ and $p<0.025$ ) (Fig. $4 A, B)$. In general, $(\Delta F / F)_{\text {LTS }}$ in mibefradil was too small to measure its rise time. This treatment also reduced the half-duration of large EPSPs that mediated $(\Delta F / F)_{\text {LTS }}$ $(81 \pm 41$ vs $53 \pm 38 \mathrm{~ms} ; n=5 ; p<0.05)$. Mibefradil had no significant effect on the amplitude of LTS EPSPs (94 $\pm 10 \%$ of control; $n=5$ ). Similar to our previous findings (Egger et al., 2003), mibefradil reduced transients attributable to somatically evoked APs $(\Delta F / F)_{\mathrm{sAP}}$ to $\sim 50 \%$ of control.

Global $\mathrm{Ca}^{2+}$ spike signals $(\Delta F / F)_{\text {LTS }}$ were also reduced by NMDA-R blockade ( $50 \mu \mathrm{M}$ APV; $58 \pm 12 \%$ of control; $n=9$ dendrites and spines; $p<0.005$ ) (Fig. $4 C, D$ ). Although the EPSP amplitude was not changed by APV ( $99 \pm 11 \%$ of control; see also below), its duration was reduced to $41 \pm 12 \%(n=6)$. Therefore and because the $\mathrm{Ca}^{2+}$ spike was entirely blocked by T-channel blockers, NMDA-Rs most likely contribute extended depolarization and thus more $\mathrm{Ca}^{2+}$ influx via $\mathrm{T}$-channels but little direct $\mathrm{Ca}^{2+}$ to $(\Delta F / F)_{\mathrm{LTS}}$ in the dendrite.

\section{Sources of calcium for local synaptic signals}

NMDA receptors are a principal pathway for synaptic $\mathrm{Ca}^{2+}$ influx in spines of hippocampal and cortical pyramidal neurons (Köster and Sakmann, 1998; Kovalchuk et al., 2000; Nevian and Sakmann, 2004) and are known to be present at the M/TC-GC synapse (Trombley and Shepherd, 1992; Isaacson and Strowbridge, 1998; Sassoe-Pognetto and Ottersen, 2000). Application of APV $(50 \mu \mathrm{M})$ reduced the synaptic $\mathrm{Ca}^{2+}$ influx into GC spines to $51 \pm 17 \%$ of the mean $(\Delta F / F)_{\text {syn }}$ amplitude $(n=9$ spines; $p<$ $0.002)$ (Fig. $5 A-C)$. There was no effect on $(\Delta F / F)_{\text {sAP }}$ in the same set of spines ( $97 \pm 20 \%$ of control). In most of our experiments (11 of 13), the application of $50 \mu \mathrm{M}$ APV did not decrease the EPSP amplitude (Fig. 5B), allowing us to exclude a decrease in $\mathrm{M} / \mathrm{TC}$ stimulation efficiency; only those experiments were considered for analysis of the calcium signal (EPSP amplitude, $97 \pm$ $11 \%$ of control; $p>0.2 ; n=11$ ). A contribution of the NMDA-R conductance to the EPSP was indicated by a significantly faster

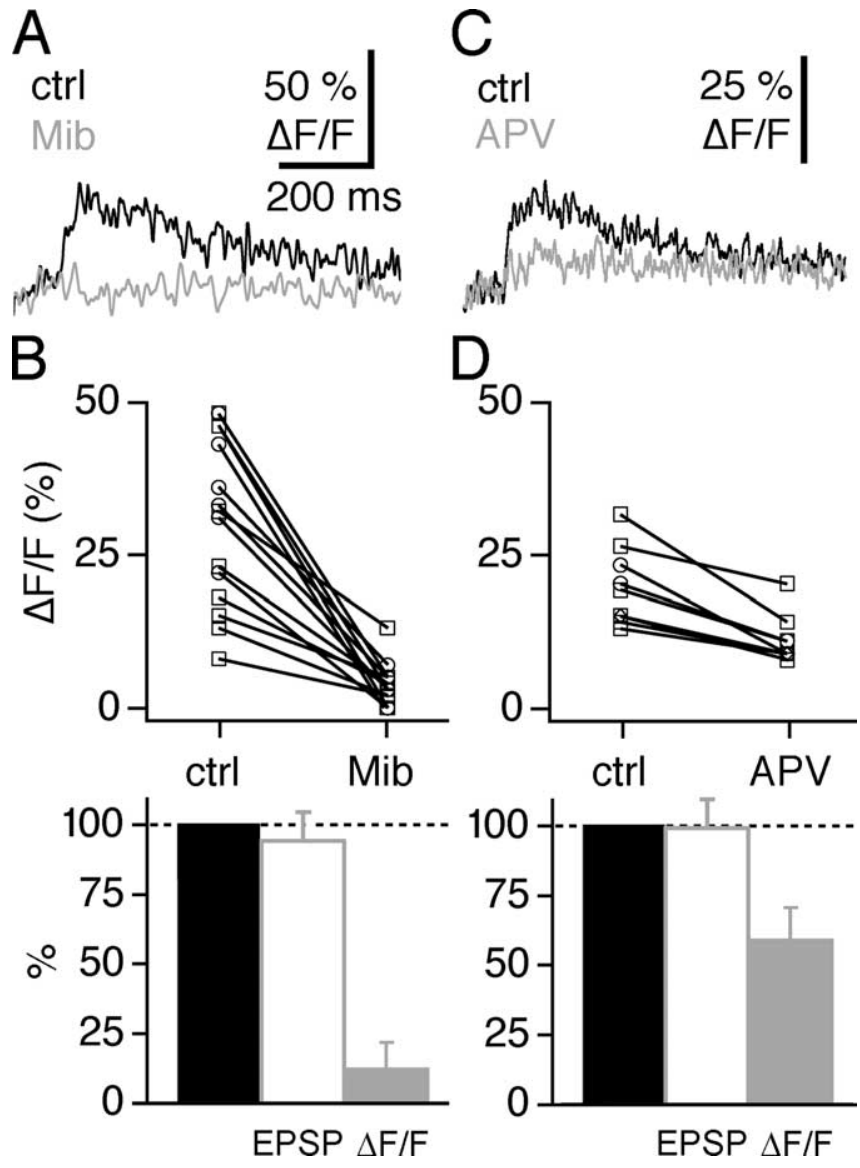

Figure 4. T-type voltage-dependent $\mathrm{Ca}^{2+}$ channels mediate the global LTS signal. $\boldsymbol{A}$, Individual experiment in a dendrite, showing the dendritic $(\Delta F / F)_{\text {LTS }}$. Black traces show averaged control responses (ctrl), and gray traces show averaged responses in $10 \mu \mathrm{m}$ mibefradil (Mib). $\boldsymbol{B}$, Cumulative display of the effect of mibefradil on $(\Delta F / F)_{\mathrm{LTS}}[n=14$ locations in dendrites (9, $\square$ ) and spines $(5, \bigcirc)]$, shown in absolute values (top) and as mean percentage change of control (gray bar, bottom). The effect of mibefradil on LTS EPSP amplitudes is shown as mean percentage change of control (white bar, bottom). C, Individual experiment in a dendrite, showing the den$\operatorname{dritic}(\Delta F / F)_{L T S}$. Black traces show averaged control responses, and gray traces show averaged responses in $10 \mu \mathrm{m}$ APV. Bottom, Corresponding averaged EPSPs. D, Cumulative display of the effect of $\operatorname{APV}$ on $(\Delta F / F)_{L T S}[n=8$ locations in dendrites $(5, \square)$ and spines $(3, O)]$, again shown in absolute values and as mean percentage change of control (gray bar). The effect of APV on LTSEPSP amplitudes is shown as mean percentage change of control (white bar).

decay of the EPSPs in APV compared with control (99 \pm 53 vs $38 \pm 13 \mathrm{~ms}$, or $43 \pm 12 \%$ of control; $n=11 ; p<0.002$ ) (Fig. $5 B$ ). APV also sped up the rise time of $(\Delta F / F)_{\text {syn }}$ to $63 \pm 33 \%$ of control ( $p<0.05 ; n=6$ spines), whereas it had no effect on the rise of $(\Delta F / F)_{\text {sAP }}$ in the same spines $(106 \pm 21 \%)$. These observations indicate that the NMDA-R conductance participates in slowing the time course of synaptic $\mathrm{Ca}^{2+}$ transients relative to sAP-evoked events.

Interestingly, in the presence of APV, synaptic calcium transients were still localized to the spine (Fig. 5A). One possible local synaptic $\mathrm{Ca}^{2+}$ source is release of $\mathrm{Ca}^{2+}$ from internal stores (Finch and Augustine, 1998; Takechi et al., 1998; Emptage et al., 1999). There is morphological evidence for the localization of the requisite cellular organelles in most GC spines (Woolf et al., 1991a). To investigate the possibility that stores might contribute to GC spine calcium transients, we applied $10 \mu \mathrm{M}$ thapsigargin, which depletes internal stores, to the bath while continuing stimulation of the GC input. After 10 min of this treatment, the amplitude of $(\Delta F / F)_{\text {syn }}$ was stably reduced to $57 \pm 21 \%$ of control 
$(n=5 ; p<0.05)$ (Fig. $6 A, B)$, although there was no consistent effect on its rise time ( $86 \pm 23 \%$ of control). There was a small effect on the amplitude of $(\Delta F / F)_{\text {sAP }}$ in the same spines $(78 \pm 8 \%$ of control). Thapsigargin did not change the EPSP amplitude (102 $\pm 8 \%$ of control; $n=5$ ) (Fig. $6 A, B)$, indicating that the drug acted postsynaptically on GC $\mathrm{Ca}^{2+}$ signals rather than by inhibiting $\mathrm{M} / \mathrm{TC}$ stimulation or release. Nor was the thapsigargin effect attributable to an increase in baseline fluorescence $\left(F_{0}, 99 \pm 27 \%\right.$ of control; $n=7$ ), excluding a rise in basal $\mathrm{Ca}^{2+}$ levels as the mechanism of action. Therefore, we conclude that release from internal stores contributes to local synaptic $\mathrm{Ca}^{2+}$ signals in GCs.

What triggered release from calcium stores in GC spines? Application of $50 \mu \mathrm{M}$ APV and $100 \mu \mathrm{M} \mathrm{Ni}^{2+}$ completely blocked the synaptic $\mathrm{Ca}^{2+}$ transient in all spines examined [ $\pm 10 \%$ of control; mean $(\Delta F /$ $F)_{\text {syn }}, 2 \pm 3 \% ; n=5 ; p<0.05 ; \chi^{2}$ test] (Fig. $5 B, D$ ), although it had little effect on the corresponding EPSP amplitudes $(80 \pm$ $16 \%$ of control; $p>0.09$ ) (Fig. $5 B, C$ ). Thus, internal stores are activated via calcium-induced calcium release (CICR) rather than via the metabotropic glutamate receptor/IP 3 pathway. This manipulation also showed that other possible ligandgated sources of synaptically gated calcium, in particular calcium-permeable AMPA receptors, play no significant role.

For spines of cultured hippocampal neurons, it has been suggested that CICR carries most of the $\mathrm{Ca}^{2+}$ signal and is triggered by an NMDA-R-mediated $\mathrm{Ca}^{2+}$ signal too small for detection (Emptage et al., 1999). Could the APV-sensitive component of the $\mathrm{Ca}^{2+}$ transient in GC spines be attributable to NMDA-R triggered CICR rather than direct NMDA-R mediated $\mathrm{Ca}^{2+}$ entry? In the continued presence of thapsigargin, APV reduced $(\Delta F /$ $F)_{\text {syn }}$ to $41 \pm 16 \%$ of its amplitude in thapsigargin alone $(n=4)$. Thus, calcium entry through NMDA-R channels contributes to GC spine signals directly and not just through CICR. The net effect of coapplied thapsigargin and APV (10 and $50 \mu \mathrm{M}$, respectively) was a block of $(\Delta F / F)_{\text {syn }}$ to $29 \pm 13 \%$ of control $(n=6$; $p<0.05$; Mann-Whitney test) (Fig. 6C). There was no significant effect on $(\Delta F / F)_{\text {sAP }}$ in the same spines $(84 \pm 30 \%$ of control; $n=$ $5)$ or on the EPSP amplitude ( $96 \pm 25 \%$ of control). The remaining $(\Delta F / F)_{\text {syn }}$ signal represents a direct contribution via $\mathrm{Ni}^{2+}$ sensitive [high-voltage-activated and LVA] VDCCs.

Because VDCCs are present on the dendrite as well as the spine (Egger et al., 2003), their participation in transients localized to the spine head implies that the depolarization opening them is restricted to the spine as well. This localization of depolarization could be attributable to a (passive) gain in voltage and subsequent attenuation via the spine neck resistance (Rall and Rinzel, 1973; Brown et al., 1988; Tsay and Yuste, 2004): The mean neck length as estimated from frame scans $128 \times 128$ pixels in size $(10 \times 10 \mu \mathrm{m})$ was $2.6 \pm 1.3 \mu \mathrm{m}(n=19)$ (data similar to that of Woolf et al., 1991a). Thus, the spine neck resistance of large granule cell spines may be considerably higher than that of the shorter spines of pyramidal or Purkinje cells (Svoboda et al., 1996) (see Discussion).
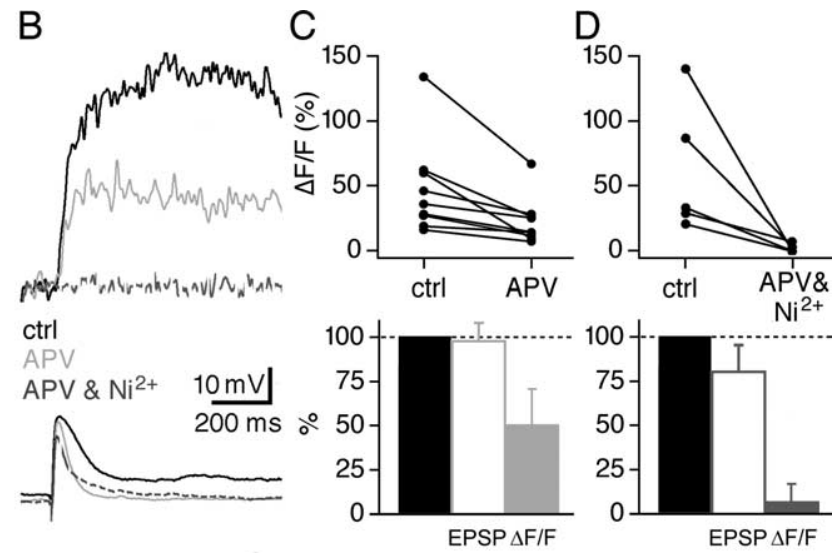

Figure 5. The local synaptic signal $(\Delta F / F)_{\text {syn }}$ is governed by a variety of $\mathrm{Ca}^{2+}$ sources, including NMDA-Rs and VDCCs. $\boldsymbol{A}$, show averaged control responses (ctrl), and gray traces show those in $10 \mu \mathrm{m}$ APV. Bottom, Scatter plot of local synaptic response the presence of 10 M APV . B Individual experiment in responsive spine. Top, $(\Delta F / F)$ in the spine. Black traces show averaged control responses, gray traces show those in $10 \mu \mathrm{m} \mathrm{APV}$, and black dashed traces show those in $10 \mu \mathrm{m} A P V$ and $100 \mu \mathrm{m}$ ( Corresponding averaged EPSPs. C Cumulative display of the effect of APV on ( $\triangle F / F)_{s y n}(n=9$ spines), shown in absolute mean percentage change of control (white bar, bottom). D Display of five individual experiments showing the absolute effect of hange of control (gray bar, bottom). The effect of coapplied APV and $\mathrm{Ni}^{2+}$ on EPSP amplitudes is shown as mean percentage change of control (white bar, bottom).
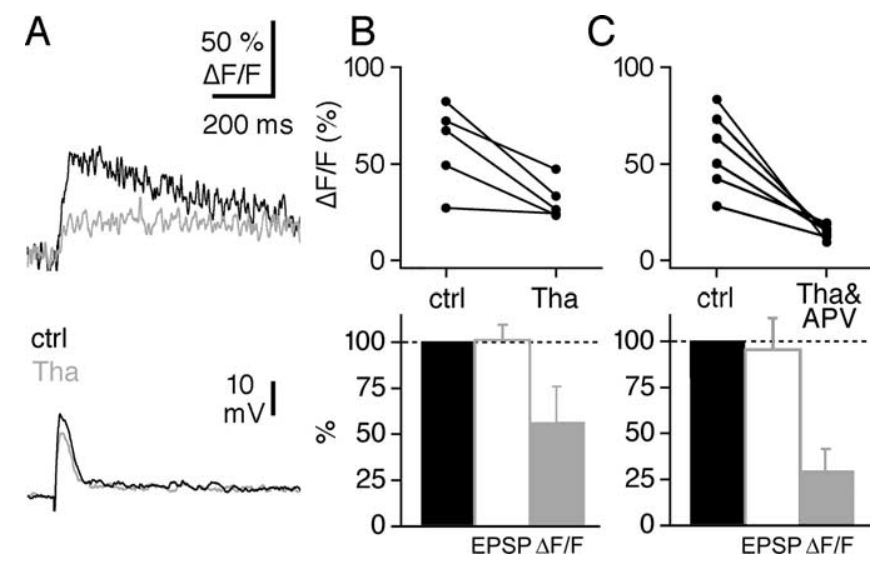

Figure 6. The local synaptic signal is governed by a variety of $\mathrm{Ca}^{2+}$ sources, including release from internal stores. $\boldsymbol{A}$, Individual experiment showing the effect of $10 \mu \mathrm{m}$ thapsigargin (Tha) on $(\Delta F / F)_{\text {syn }}$ in a responsive spine and the corresponding averaged EPSP. $B$, Cumulative display of the effect of thapsigargin on $(\Delta F / F)_{\text {syn }}(n=5$ spines), shown in absolute values (top) and as mean percentage change of control (ctrl) (gray bar, bottom). The effect of thapsigargin on EPSP amplitudes is shown as mean percentage change of control (white bar). C, Display of six experiments showing the effect of coapplied $10 \mu \mathrm{m}$ thapsigargin and $10 \mu \mathrm{m} A P V$ on $(\Delta F / F)_{\text {syn }}$ in a spine in absolute values and as mean percentage change of control (gray bar, bottom). The effect of coapplied thapsigargin and APV on EPSP amplitudes is shown as mean percentage change of control (white bar).

Spine voltage boosting could be particularly important in GC spines because of the presence of T-type calcium channels (Egger et al., 2003), which are activated at relatively low voltages. To test the contribution of T-channels to local synaptic $\mathrm{Ca}^{2+}$ transients, we applied mibefradil $(10 \mu \mathrm{M})$. This manipulation reduced $(\Delta F /$ $F)_{\text {syn }}$ amplitudes to $71 \pm 10 \%$ of control (GC at resting potential of approximately $-70 \mathrm{mV}$ before stimulation; $p<0.05 ; n=5$ ), although it had no discernible effect on the rise times of $(\Delta F / F)_{\text {syn }}$ $(101 \pm 22 \%)$ or $(\Delta F / F)_{\text {sAP }}(103 \pm 33 \%)$ (cf. Egger et al., 2003). 
A
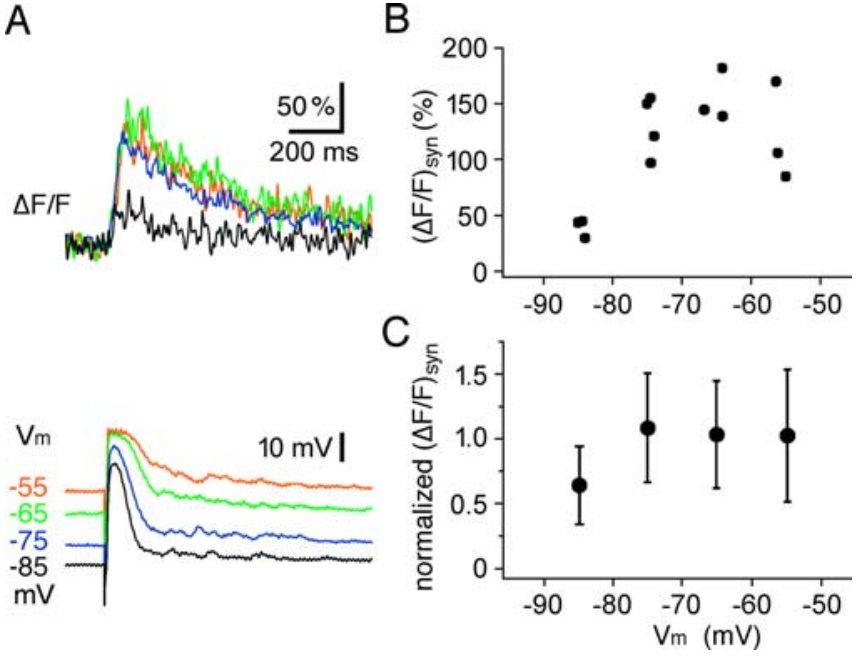

Figure 7. The voltage dependence of local synaptic transients is only in part governed by NMDA receptors. $A$, Individual experiment. Top, Averaged $(\Delta F / F)_{\text {syn }}$ responses at various holding potentials. Bottom, Corresponding averaged EPSPs. Note the reduction in absolute maximal depolarization by the EPSP with hyperpolarization. $B$, Plot of individual $(\Delta F / F)_{\text {syn }}$ response amplitudes recorded in the same cell as in $A$. C, Cumulative $(\Delta F / F)_{\text {syn }}$ amplitude data from nine spines in seven cells. First, data from individual spines were normalized to the amplitude values $(\Delta F / F)_{\text {syn }}$ in that spine at the resting membrane potential $(-70 \mathrm{mV})$. Data from all spines were then averaged within a bin width of $10 \mathrm{mV}$.

Because coapplied APV and thapsigargin block more of $(\Delta F /$ $F)_{\text {syn }}$ than APV alone ( $\sim 70$ vs $\sim 50 \%$ reduction $), \mathrm{Ca}^{2+}$ entry through VDCCs could also contribute to CICR. Which VDCCs? The global LTS $\mathrm{Ca}^{2+}$ signals invade GC spines and are mediated by T-channels. Whereas thapsigargin $(10 \mu \mathrm{M})$ had some effect on $(\Delta F / F)_{\mathrm{sAP}}(78 \pm 8 \%$ of control; $n=4)$, which is carried by HVA and T-channels, it had no effect on $(\Delta F / F)_{\text {LTS }}(97 \pm 18 \% ; n=3$ cells), which is carried by T-channels alone. Together, these data suggest that $\mathrm{T}$-channels are not likely to contribute substantially to synaptically evoked CICR.

Voltage dependence of synaptic signals in responsive spines To elucidate the role of VDCCs versus NMDA-Rs for local synaptic $\mathrm{Ca}^{2+}$ signals, we varied the membrane potential of the GC within sub-AP-threshold ranges (resting potential, $-72 \pm 3 \mathrm{mV}$; $n=24)$. If there was indeed a local spine voltage boost in GC spines and most of the $\mathrm{Ca}^{2+}$ entry was carried by VDCCs, synaptic $\mathrm{Ca}^{2+}$ signals should be reduced by both hyperpolarization and depolarization because hyperpolarized holding potentials will prevent VDCC activation and depolarized potentials will inactivate VDCCs. NMDA-R-mediated $\mathrm{Ca}^{2+}$ entry, however, should also be blocked by hyperpolarization but increase with depolarization. We demonstrated previously that somatically applied polarization propagates faithfully into the GC dendrite (Egger et al., 2003, their Fig. 4C).

Hyperpolarization to -80 to $-90 \mathrm{mV}$ produced a pronounced inhibition of synaptic transients $(\Delta F / F)_{\text {syn }}$ in all cells ( $n=9$ spines in 7 cells; $p<0.001$; Kruskal-Wallis test) (Fig. 7). Although there was an increase in somatic EPSP amplitudes with hyperpolarization, it did not entirely compensate the voltage drop induced by hyperpolarization (Fig. $7 A$ ). The inhibition of $(\Delta F / F)_{\text {syn }}$ by hyperpolarization can be interpreted as a failure to create sufficient AMPA-R-mediated depolarization to activate VDCC channels or relieve $\mathrm{Mg}^{2+}$ block of NMDA-Rs.

Depolarization to -60 to $-50 \mathrm{mV}$ revealed no increase in calcium transient amplitudes, contrary to what would be ex-

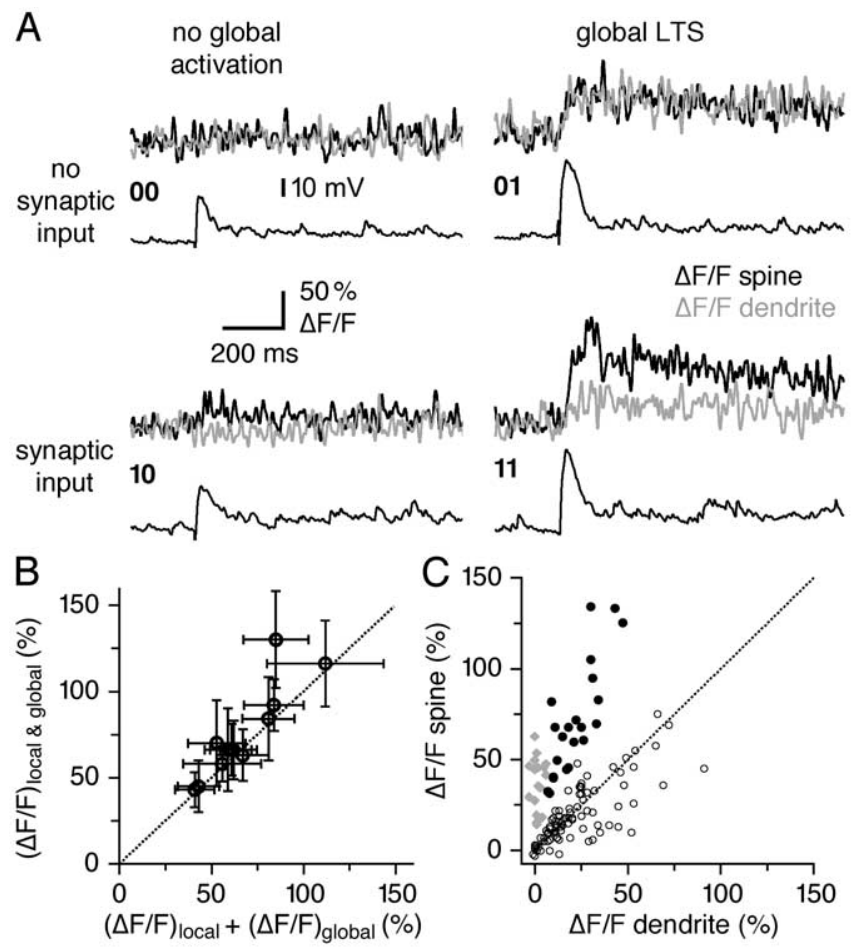

Figure 8. Global and local $\mathrm{Ca}^{2+}$ signals summate in individual spines. A, Response "matrix" for global and/or local activation in an individual spine. All responses shown are individual trials and were recorded at the same stimulation strength. Black bottom traces represent EPSPS recorded at the GC soma, black top traces represent $\Delta F / F$ in a spine, and gray top traces represent $\Delta F / F$ in the adjacent dendrite. 00 , Neither local nor global activation. 10, Local activation of the synapse; note the localization of the transient to the spine. 01, Global EPSP/LTS signal without local synaptic activation; similar transient amplitudes in dendrites. 11, Local and global activation. Note the broader, different shape and larger amplitude of the global EPSP in its voltage traces in 01 and 11. $\boldsymbol{B}$, Cumulative summation data from 12 spines. Scatter plot of summed averaged local and global signal amplitudes versus actual combined signal amplitude. The dashed line corresponds to linear summation. C, Averaged spine versus adjacent dendrite $\Delta F / F$ amplitudes of local synaptic activation (gray diamonds; $n=39$, including the 12 summation spines), LTS activation (white circles; $n=80$ ), and spines with combined activation (O) $n=24$, including the 12 summation spines).

pected for exclusively NMDA-R-mediated signals. Instead, a plateau was observed (Fig. 7). The plateau was not attributable to an increased baseline fluorescence, because the average $F_{0}$ did not change significantly with voltage (average $F_{0}$ in -60 to $-50 \mathrm{mV}$ interval, $106 \pm 22 \%$ of control at $-70 \mathrm{mV} ; n=22$ measurements in 9 spines; see Materials and Methods). Thus, the voltage dependence of synaptic transients in GC spines is consistent with the idea that both NMDA-Rs and VDCCs contribute to spine $\mathrm{Ca}^{2+}$ signals, with partial inactivation of VDCCs possibly balancing increased NMDA-R contribution at more depolarized potentials.

\section{Cooperation of local and global mode of activation}

To examine interactions of global and local calcium signals at individual spines, we took advantage of the stochasticity of both of these signals at many spines. Figure $8 \mathrm{~A}$ shows a set of individual trials representing the four possible responses in the same single spine: no activation, i.e., failure of local synaptic activation and no global LTS (00); local synaptic release and no global activation (10); synaptic failure and global activation (01); and both local and global synaptic activation (11). The occurrence of the global LTS signal, $(\Delta F / F)_{\text {LTS }}$, was always clearly marked by dendritic activation and a larger, broadened EPSP. The average local and LTS-mediated signals were similar in size, although the com- 
bined activation was significantly larger: $10,34 \pm 10 \% ; 01,33 \pm$ $13 \% ; 11,74 \pm 26 \%(n=12$ spines; 10 or 01 vs $11, p<0.002)$. The ratio of the combined signal $(\Delta F / F)_{11}$ to the sum of the individual components $\left[(\Delta F / F)_{10}+(\Delta F / F)_{01}\right]$ in a spine was $1.11 \pm 0.16$ ( $n=12$ spines) (Fig. $8 B$ ). Thus, the $\mathrm{Ca}^{2+}$ signals attributable to synaptic and global activation summate approximately linearly within the spine. In other active spines, we always observed a global LTS $\mathrm{Ca}^{2+}$ signal. In these spines, the dendritic component and a similar fraction of the spine component were attributable to the $\mathrm{Ca}^{2+}$ spike, as described above (spine, $74 \pm 30 \% \Delta F / F$; dendrite, $25 \pm 14 \% \Delta F / F ; n=12$ ) (Fig. $8 C$ ).

\section{Discussion}

\section{Local and global subthreshold calcium signaling}

These results provide the first direct documentation of the mechanisms of synaptically evoked dendrodendritic calcium signals in olfactory bulb granule cells, an axonless cell type with dendrites that act as both presynaptic (transmitter-releasing) and postsynaptic (transmitter-receiving) elements. We observed two forms of AP-independent calcium signaling with very different properties. (1) Local $\mathrm{Ca}^{2+}$ transients were strictly confined to individual activated spines and were carried by NMDA-Rs, VDCCs, and release from internal stores. (2) Global LTS encompassed the entire dendritic tree and were mediated by T-type $\mathrm{Ca}^{2+}$ channel activation (see supplemental Fig. 1, available at www.jneurosci. org as supplemental material). These two signals provide strong candidate mechanisms for the two principal AP-independent circuit functions of olfactory bulb GCs, M/TC self inhibition and M/TC lateral inhibition (Jahr and Nicoll, 1982; Isaacson and Strowbridge, 1998; Schoppa et al., 1998; Shepherd and Greer, 1998). Consistent with their differing sources, global and local signals interacted quasi-independently within individual spines. Thus, we also observed a third distinct GC activation mode, defined by the coincidence of local and global signals.

\section{Spine transients: chemical and electrical compartmentalization?}

Synaptic $\mathrm{Ca}^{2+}$ transients in GC spines attributable to M/TC inputs were highly localized to the spine head. We previously observed spontaneous synaptic transients in GC spines that might have arisen from either M/TC or else centrifugal synapses (Egger et al., 2003). Here, using glomerular stimulation, we mimicked the sensory-activation pathway, thus establishing that localization is characteristic for $\mathrm{M} / \mathrm{T}$ cell input to GCs. Because the shorter spines of other neuronal classes show less compartmentalization under similar conditions (Yuste and Denk, 1995; Köster and Sakmann, 1998; Kovalchuk et al., 2000; Nevian and Sakmann, 2004), this property may be attributable to the long neck of GC spines (our unpublished data) (Woolf et al., 1991a). The strict localization demonstrates that, assuming that these transients are sufficient for release, M/TC self-inhibition exists in a pure form in which a local reciprocal microcircuit is activated without any lateral spread.

The function of such pure self-inhibition, which appears unique to GCs, is yet unclear. It is worth noting that the reciprocal microcircuit presents a more diverse set of mechanisms for dynamically regulating the strength of negative feedback compared with simple cell-autonomous inhibitory mechanisms (e.g., $\mathrm{Ca}^{2+}$-activated $\mathrm{K}^{+}$channels). In the olfactory system, this negative feedback could be enhanced, for example, via centrifugal activation of large GC spines (Price and Powell, 1970). However, persistent top-down excitation of GCs could also result in disinhibition of M/TCs via inactivation of GC T-type $\mathrm{Ca}^{2+}$ channels (see below) (Egger et al., 2003). In either case, top-down regulation of M/TC self-inhibition could thus be used to create "search images" or templates for certain relevant odors: by promoting inhibition or excitation of certain groups of M/TCs

Spine $\mathrm{Ca}^{2+}$ transients were carried by a variety of sources, including NMDA-Rs, VDCCs, and CICR, but not $\mathrm{Ca}^{2+}$ entry through AMPA-Rs entry (cf. Jardemark et al., 1997). According to our data, CICR is triggered by $\mathrm{Ca}^{2+}$ entry via both NMDA-Rs and VDCCs. Although the respective roles of these diverse signals remain to be elucidated, it is an interesting possibility that separable functions are achieved, perhaps via microdomains within the spine. The fact that localization to the spine head was observed even for the VDCC-mediated component of the spine calcium signal was surprising, because we knew from previous work that similar complements of VDCCs are present on both GC dendrites and spine (Egger et al., 2003). For VDCC-mediated $\mathrm{Ca}^{2+}$ signals to remain localized, there needs to be not only chemical compartmentalization but also electrical compartmentalization; otherwise, synaptic depolarization would also activate dendritic VDCCs. Although it is possible that VDCCs in spines have lower activation voltages than VDCCs in dendrites, we observed no consistent differences in the kinetics or amplitudes of spine and dendritic $\mathrm{Ca}^{2+}$ transients produced by APs (Egger et al., 2003) or step depolarization to $-40 \mathrm{mV}$ (V. Egger and Z. F. Mainen, unpublished observations). Thus, localization of depolarization is most likely attributable to the high input impedance and low neck conductance of the spine relative to the size of the synaptic conductance (Rall and Rinzel, 1973; Brown et al., 1988; Tsay and Yuste, 2004). The intriguing question remains whether a similar degree of isolation holds for the subset of small GC spines that receive mostly centrifugal input (Price and Powell, 1970).

Local activation of HVA (N/P/Q-type) channels in selfinhibition (Isaacson, 2001) would imply a relatively large spine voltage transient, perhaps even a regenerative event, i.e., a "spine spike" (Shepherd and Brayton, 1987; Segev and Rall, 1988; Softky, 1994; Tsay and Yuste, 2004). However, because feedback inhibition works also independently of $\mathrm{Na}^{+}$channels ( $\mathrm{Jahr}$ and Nicoll, 1982; Isaacson and Strowbridge, 1998), such spine spikes would correspond to regenerative $\mathrm{Ca}^{2+}$ spikes and would not necessarily involve sodium APs.

\section{Low-threshold spike: a novel subthreshold global "presynaptic" signal}

In this study, we documented a novel subthreshold mode of $\mathrm{Ca}^{2+}$ signaling between different GC spines, a global LTS. Like APevoked $\mathrm{Ca}^{2+}$ signals (Egger et al., 2003), the LTS was all-or-none in nature. The LTS signal was of a similar magnitude to APevoked $\mathrm{Ca}^{2+}$ signals, and, like the AP-evoked signal, the LTS spread globally throughout the dendrites, similar to observations in turtle olfactory bulb GCs by Pinato and Midtgaard (2004). Thus, the LTS represents a putative "presynaptic" signal that we propose to underlie AP-independent lateral inhibition between M/TCs. We saw no evidence for the regionally localized $\mathrm{Ca}^{2+}$ signals described in some cell types (Eilers et al., 1995; Schiller et al., 1997; Wei et al., 2001) and proposed for GCs on theoretical grounds (Woolf et al., 1991a; Woolf and Greer, 1994); in our experiments, LTS-mediated lateral inhibition was never spatially restricted to subregions of the GC dendrite. However, regional LTS signals might be produced under different conditions, for example, shunting by ongoing synaptic input to GCs (Koch et al., 1982), different in vivo activation patterns, modulation by centrifugal input, or developmental changes of network properties. 
Yet another type of regional $\mathrm{Ca}^{2+}$ signal, perhaps attributable to spatially restricted $\mathrm{Na}^{+}$spikes (spikelets) (Wellis and Scott, 1990; Luo and Katz, 2001; Pinato and Midtgaard, 2004), has been observed in frog olfactory bulb GC dendrites (K. Delaney, personal communication).

T-channels mediate all of the LTS-mediated and $~ 30 \%$ of the local synaptic $\mathrm{Ca}^{2+}$ signal (this study), as well as $\sim 50 \%$ of sAPmediated $\mathrm{Ca}^{2+}$ signals (Egger et al., 2003). Unlike in other T-channel-bearing neurons such as thalamocortical relay cells, T-channels appear to play less of a role in sculpting GC firing properties (Egger et al., 2003). We suggest that T-channelmediated $\mathrm{Ca}^{2+}$ transients may represent sufficient signals to evoke vesicular release (cf. Egger et al., 2003). So far, T-channels have only been implicated in synaptic release in the retina (Pan et al., 2001). Direct confirmation of this proposal will require monitoring measurement of GC release in conjunction with imaging experiments, a procedure that has proven technically difficult because of the low incidence of GC-M/TC synapses (Egger et al., 2003).

Insofar as T-type $\mathrm{Ca}^{2+}$ channels contribute to GC-mediated lateral inhibition in the olfactory bulb, they could provide a mechanism for controlling the gain of GC output via persistent input, or the slow, respiration-related oscillations within the olfactory bulb (Macrides and Chorover, 1972), similar to the previously proposed role for T-channels in the global GC sAPmediated $\mathrm{Ca}^{2+}$ signal (Egger et al., 2003). These mechanisms would imply a role for T-channels in gating the entry of olfactory information to the cortex, analogous to the role they play in thalamocortical relay cells (Huguenard, 1996).

\section{Independent $\mathrm{GC} \mathrm{Ca}^{2+}$ signaling modes: coincidence detection?}

In cortical and hippocampal pyramidal cells, backpropagating action potentials (Magee and Johnston, 1997; Markram et al., 1997) and distal dendritic calcium spikes (Golding et al., 2002) can cooperate with local synaptic activity in the induction of long-term plasticity. Interestingly, our results indicate that subthreshold coincidence detection could also be performed by local and global $\mathrm{Ca}^{2+}$ signals in GC spines. Consistent with their mostly distinct sources, these $\mathrm{Ca}^{2+}$ signals acted quasiindependently. That is, we observed approximately linear summation of local and global subthreshold synaptic signals in the GC spine (Fig. 8). The apparent linearity could rely on a balance of increases and decreases attributable to coincidence of signals: $\mathrm{Ca}^{2+}$ influx via NMDA-Rs increases attributable to the depolarization provided by the global signal (Schiller et al., 1998), whereas the contribution of VDCCs decreases because of inactivation and competitive activation by both pathways. The marked increase of $\mathrm{Ca}^{2+}$ influx attributable to subthreshold coincident global and local (i.e., presynaptic and postsynaptic) activation of a GC spine would represent a novel mechanism for Hebbian synaptic plasticity within the spine microcircuit.

\section{References}

Brown TH, Chang VC, Ganong AH, Keenan CL, Kelso SR (1988) Biophysical properties of dendrites and spines that may control the induction and expression of long-term synaptic potentiation. In: Long-term potentiation: from biophysics to behavior (Landfield PW, Deadwyler SA, eds), pp 201-264. New York: Wiley.

Cang J, Isaacson JS (2003) In vivo whole-cell recording of odor-evoked synaptic transmission in the rat olfactory bulb. J Neurosci 23:4108-4116.

Carleton A, Petreanu LT, Lansford R, Alvarez-Buylla A, Lledo PM (2003) Becoming a new neuron in the adult olfactory bulb. Nat Neurosci 6:507-518.
Chen WR, Shepherd GM (1997) Membrane and synaptic properties of mitral cells in slices of rat olfactory bulb. Brain Res 745:189-196.

Chen WR, Xiong W, Shepherd GM (2000) Analysis of relations between NMDA receptors and GABA release at olfactory bulb reciprocal synapses. Neuron 25:625-633.

Egger V, Svoboda K, Mainen ZF (2003) Mechanisms of lateral inhibition in the olfactory bulb: efficiency and modulation of spike-evoked calcium influx into granule cells. J Neurosci 23:7551-7559.

Eilers J, Augustine GJ, Konnerth A (1995) Suprathreshold synaptic $\mathrm{Ca}^{2+}$ signalling in fine dendrites and spines of cerebellar Purkinje neurons. Nature 373:155-157.

Emptage NJ, Bliss TV, Fine A (1999) Single synaptic events evoke NMDA receptor-mediated release of calcium from internal stores in hippocampal dendritic spines. Neuron 22:115-124.

Finch EA, Augustine GJ (1998) Local calcium signalling by inositol-1,4,5trisphosphate in Purkinje cell dendrites. Nature 396:753-756.

Golding NL, Staff NP, Spruston N (2002) Dendritic spikes as a mechanism for cooperative long-term potentiation. Nature 418:326-331.

Halabisky B, Friedman D, Radojicic M, Strowbridge BW (2000) Calcium influx through NMDA receptors directly evokes GABA release in olfactory bulb granule cells. J Neurosci 20:5124-5134.

Hamilton KA, Kauer JS (1988) Responses of mitral/tufted cells to orthodromic and antidromic electrical stimulation in the olfactory bulb of the tiger salamander. J Neurophysiol 59:1736-1755.

Huguenard JR (1996) Low-threshold calcium currents in central nervous system neurons. Annu Rev Physiol 58:329-348.

Isaacson JS (2001) Mechanisms governing dendritic gamma-aminobutyric acid (GABA) release in the rat olfactory bulb. Proc Natl Acad Sci USA 98:337-342.

Isaacson JS, Strowbridge BW (1998) Olfactory reciprocal synapses: dendritic signaling in the CNS. Neuron 20:749-761.

Jahr CE, Nicoll RA (1980) Dendrodendritic inhibition: demonstration with intracellular recording. Science 207:1473-1475.

Jahr CE, Nicoll RA (1982) An intracellular analysis of dendrodendritic inhibition in the turtle in vitro olfactory bulb. J Physiol (Lond) 326:213-234

Jardemark K, Nilsson M, Muyderman H, Jacobson I (1997) $\mathrm{Ca}^{2+}$ ion permeability properties of $(R, S)$ alpha-amino-3-hydroxy-5-methyl-4isoxazolepropionate (AMPA) receptors in isolated interneurons from the olfactory bulb of the rat. J Neurophysiol 77:702-708.

Koch C (1999) Biophysics of computation. New York: Oxford UP.

Koch C, Poggio T, Torre V (1982) Retinal ganglion cells: a functional interpretation of dendritic morphology. Philos Trans R Soc Lond B Biol Sci 298:227-264.

Köster HJ, Sakmann B (1998) Calcium dynamics in single spines during coincident pre- and postsynaptic activity depend on relative timing of back-propagating action potentials and subthreshold excitatory postsynaptic potentials. Proc Natl Acad Sci USA 95:9596-9601.

Kovalchuk Y, Eilers J, Lisman J, Konnerth A (2000) NMDA receptormediated subthreshold $\mathrm{Ca}^{2+}$ signals in spines of hippocampal neurons. J Neurosci 20:1791-1799.

Lagier S, Carleton A, Lledo P-M (2004) Interplay between local GABAergic interneurons and relay neurons generates $\gamma$ oscillations in the rat olfactory bulb. J Neurosci 24:4382-4392.

Luo M, Katz LC (2001) Response correlation maps of neurons in the mammalian olfactory bulb. Neuron 32:1165-1179.

Macrides F, Chorover SL (1972) Olfactory bulb units: activity correlated with inhalation cycles and odor quality. Science 175:84-87.

Magee JC, Johnston D (1997) A synaptically controlled associative signal for hebbian plasticity in hippocampal neurons. Science 275:209-212.

Mainen ZF, Malinow R, Svoboda KS (1999a) Synaptic calcium transients in single spines indicate that NMDA receptors are not saturated. Nature 399:151-155.

Mainen ZF, Maletic-Savatic M, Shi SH, Hayashi Y, Malinow R, Svoboda K (1999b) Two-photon imaging in living brain slices. Methods 18:231-239.

Margrie TW, Schaefer AT (2003) Theta oscillation coupled spike latencies yield computational vigour in a mammalian sensory system. J Physiol (Lond) 546:363-374.

Margrie TW, Sakmann B, Urban NN (2001) Action potential propagation in mitral cell lateral dendrites is decremental and controls recurrent and 
lateral inhibition in the mammalian olfactory bulb. Proc Natl Acad Sci USA 98:319-324.

Markram H, Sakmann B (1994) Calcium transients in dendrites of neocortical neurons evoked by single subthreshold excitatory postsynaptic potentials via low-voltage-activated calcium channels. Proc Natl Acad Sci USA 91:5207-5211.

Markram H, Lübke J, Frotscher M, Sakmann B (1997) Regulation of synaptic efficacy by coincidence of post-synaptic APs and EPSPs. Science 275:213-215.

Mel BW (1993) Synaptic integration in an excitable dendritic tree. J Neurophysiol 70:1086-1101.

Miyakawa H, Ross WN, Jaffe D, Callaway JC, Lasser-Ross N, Lisman JE, Johnston D (1992) Synaptically activated increases in $\mathrm{Ca}^{2+}$ concentration in hippocampal CA1 pyramidal cells are primarily due to voltagegated $\mathrm{Ca}^{2+}$ channels. Neuron 9:1163-1173.

Nevian T, Sakmann B (2004) Single spine $\mathrm{Ca}^{2+}$ signals evoked by coincident EPSPs and backpropagating action potentials in spiny stellate cells of layer 4 in the juvenile rat somatosensory barrel cortex. J Neurosci 24:1689-1699.

Pan ZH, Hu HJ, Perring P, Andrade R (2001) T-type $\mathrm{Ca}^{2+}$ channels mediate neurotransmitter release in retinal bipolar cells. Neuron 32:89-98.

Petreanu L, Alvarez-Buylla A (2002) Maturation and death of adult-born olfactory bulb granule neurons: role of olfaction. J Neurosci 22:6106-6113.

Pinato G, Midtgaard J (2003) Regulation of granule cell excitability by a low-threshold calcium spike in turtle olfactory bulb. J Neurophysiol 90:3341-3351.

Pinato G, Midtgaard J (2004) Dendritic sodium spikelets and low-threshold calcium spikes in turtle olfactory bulb granule cells. J Neurophysiol 93:1285-1294.

Pologruto TA, Sabatini BL, Svoboda K (2003) ScanImage: flexible software for operating laser scanning microscopes. Biomed Eng Online 2:13.

Polsky A, Mel BW, Schiller J (2004) Computational subunits in thin dendrites of pyramidal cells. Nat Neurosci 7:621-627.

Price JL, Powell TP (1970) An experimental study of the origin and the course of the centrifugal fibres to the olfactory bulb in the rat. J Anat 107:215-237.

Rall W, Rinzel J (1973) Branch input resistance and steady attenuation for input to one branch of a dendritic neuron model. Biophys J 13:648-687.

Rall W, Shepherd GM, Reese TS, Brightman MW (1966) Dendrodendritic synaptic pathway for inhibition in the olfactory bulb. Exp Neurol 14:44-56.

Sassoe-Pognetto M, Ottersen OP (2000) Organization of ionotropic glutamate receptors at dendrodendritic synapses in the rat olfactory bulb. J Neurosci 20:2192-2201.

Schiller J, Schiller Y, Stuart G, Sakmann B (1997) Calcium action potentials restricted to distal apical dendrites of rat neocortical pyramidal neurons. J Physiol (Lond) 505:605-616.

Schiller J, Schiller Y, Clapham DE (1998) NMDA receptors amplify calcium influx into dendritic spines during associative pre- and postsynaptic activation. Nat Neurosci 1:114-118.

Schoppa NE, Westbrook GL (1999) Regulation of synaptic timing in the olfactory bulb by an A-type potassium current. Nat Neurosci 2:1106-1113.

Schoppa NE, Kinzie JM, Sahara Y, Segerson TP, Westbrook GL (1998) Dendrodendritic inhibition in the olfactory bulb is driven by NMDA receptors. J Neurosci 18:6790-6802.

Segev I, Rall W (1988) Computational study of an excitable dendritic spine. J Neurophysiol 60:499-523.

Shepherd GM (1963) Responses of mitral cells to olfactory nerve volleys in the rabbit. J Physiol (Lond) 168:89-100.

Shepherd GM, Brayton RK (1987) Logic operations are properties of computer-simulated interactions between excitable dendritic spines. Neuroscience 21:151-165.

Shepherd GM, Greer CA (1998) The olfactory bulb. In: The synaptic organization of the brain (Shepherd GM, ed), pp 133-169. New York: Oxford UP.

Softky W (1994) Sub-millisecond coincidence detection in active dendritic trees. Neuroscience 58:13-41.

Svoboda K, Tank DW, Denk W (1996) Direct measurement of coupling between dendritic spines and shafts. Science 272:716-719.

Takechi H, Eilers J, Konnerth A (1998) A new class of synaptic response involving calcium release in dendritic spines. Nature 396:757-760.

Tsay D, Yuste R (2004) On the electrical function of dendritic spines. Trends Neurosci 27:77-83.

Trombley PQ, Shepherd GM (1992) Noradrenergic inhibition of synaptic transmission between mitral and granule cells in mammalian olfactory bulb cultures. J Neurosci 12:3985-3991.

Wachowiak M, Denk W, Friedrich RW (2004) Functional organization of sensory input to the olfactory bulb glomerulus analyzed by two-photon calcium imaging. Proc Natl Acad Sci USA 101:9097-9102.

Wei DS, Mei YA, Bagal A, Kao JP, Thompson SM, Tang CM (2001) Compartmentalized and binary behavior of terminal dendrites in hippocampal pyramidal neurons. Science 293:2272-2275.

Wellis DP, Scott JW (1990) Intracellular responses of identified rat olfactory bulb interneurons to electrical and odor stimulation. J Neurophysiol 64:932-947.

Woolf TB, Greer CA (1994) Local communication within dendritic spines: models of second messenger diffusion in granule cell spines of the mammalian olfactory bulb. Synapse 17:247-267.

Woolf TB, Shepherd GM, Greer CA (1991a) Serial reconstructions of granule cell spines in the mammalian olfactory bulb. Synapse 7:181-192.

Woolf TB, Shepherd GM, Greer CA (1991b) Local information processing in dendritic trees: subsets of spines in granule cells of the mammalian olfactory bulb. J Neurosci 11:1837-1854.

Xiong W, Chen WR (2002) Dynamic gating of spike propagation in the mitral cell lateral dendrites. Neuron 34:115-126.

Yuste R, Denk W (1995) Dendritic spines as basic functional units of neuronal integration. Nature 375:682-685. 